\title{
Fairness, Compulsory Vaccination, and Conscientious Objection
}

\begin{abstract}
This chapter presents an argument for compulsory vaccination and against allowing non-medical vaccine exemptions. The argument is based on the idea that the proper aim of vaccination policies should be not only herd immunity but also a fair distribution of the burdens entailed by its realization. I argue that a fairness requirement need not and should not be constrained by a principle of liberty and a principle of least restrictive alternative. Indeed, I argue how compulsory vaccination is more successful than other types of vaccination policies at satisfying the principles of fairness, least restrictive alternative, and maximizing expected utility, once these principles have been properly understood.
\end{abstract}

Keywords Fairness • Compulsion • Compulsory vaccination • Conscientious objection

\section{Implications of the Principle of Least Restrictive}

\section{Alternative}

In the previous chapter, I have suggested that if we assume that the realization of herd immunity is the goal of vaccination policies, then according to the principle of least restrictive alternative (PLRA), there are ethical reasons to implement the least restrictive policy capable of achieving that

A. Giubilini, The Ethics of Vaccination, Palgrave Studies in Ethics and Public Policy, https://doi.org/10.1007/978-3-030-02068-2_4 
goal, where restrictiveness is measured in terms of degree of limitation of individual autonomy or liberty. In this chapter, I am going to question that assumption.

Before doing that, let me first emphasize two implications of the discussion in the last chapter. First, as we saw, within that perspective, compulsory vaccination should be seen as a measure of last resort: depending on the socio-economic and cultural context, some of the less restrictive options discussed in Chap. 3 could be sufficient for the realization of herd immunity. Convincing people to vaccinate without coercing them is always preferable, and where some coercion is necessary to achieve herd immunity, a lower degree of coercion is always preferable. Besides, coercive policies would be necessary only where outright vaccine refusal is a significant factor in low vaccination rates; where this is not the case, alternative and less restrictive policies such as nudging, improving accessibility and minimizing logistic barriers to vaccination are not only ethically preferable on the basis of the PLRA but probably also very effective (Beard et al. 2017).

Second, in virtue of the same PLRA, in case of certain coercive vaccination policies such as mandatory vaccination, it makes good ethical sense to grant non-medical exemptions or "conscientious objection" to people who are opposed to vaccines. Since one of the parameters for measuring restrictiveness is the amount of people who are burdened with restrictions on liberty or autonomy (the other being the magnitude of autonomy restriction for the worse off), it seems we should grant non-medical exemptions to a certain number of people who have deeply held beliefs against vaccination, provided they are not too large a group. A policy that restricts the liberty of fewer people is preferable to one that restricts the liberty of more people. If conscientious objectors constitute, say, $2 \%$ of the population in a given jurisdiction, a PLRA would demand that these people be exempted from vaccination mandates, provided that the number of those exempted for medical or age-related reasons is also sufficiently low to guarantee that the total number of exemptions does not compromise herd immunity.

As is the case with many other instances of conscientious objection, particularly in the medical context (e.g., doctors' conscientious objection to performing abortions), one problem is that, once conscientious objection is allowed, it is difficult to keep exemption rates sufficiently low without introducing some discrimination between those who are granted exemptions and those who are not (Giubilini 2014). Moreover, as is always the case whenever the obscure notion of "conscience" (Giubilini 2016) is 
brought up, many would appeal to conscience for mere reasons of convenience, such as the desire to free-ride on herd immunity. Thus, for instance, in the US, where child vaccination is a condition for enrolling children in day care or state schools, the vast majority of states allow conscientious objection, and almost all these states saw a twofold increase of exemption rates from the 2005-06 to the 2012-13 school year. In some cases, such increase threatened herd immunity; for example, exemption rates in Oregon increased from 3.4\% to $6.4 \%$ over the same period (Wang et al. 2014). However, even where conscientious objection is normally granted, it might be possible to achieve herd immunity by making the exemption procedure particularly burdensome-for example, by requiring objecting parents to attend vaccine information sessions or to go through certain bureaucratic procedures - thus discouraging as many people as possible from applying for exemptions (Salmon and Siegel 2001; Bester 2015; Navin and Largent 2017). As Mark Navin and Mark Largent (2017) have argued, burdensome exemption procedures are likely to be the most ethical vaccination policies, since they promote both (parental) freedom not to vaccinate and effectiveness in boosting vaccination rates above the herd immunity threshold. Indeed, if and where such policies are actually effective, Navin and Largent seem to have a point. I will say more about conscientious objection and burdensome exemption procedures in the conclusion of the chapter.

These two implications of the PLRA-namely, that compulsory vaccination is a measure of last resort and that a certain number of conscientious objections to vaccination should be tolerated-are consistent with the idea that there can be pragmatic reasons for aiming at universal vaccination coverage, which is very likely to require unqualified compulsory vaccination. By "unqualified compulsory vaccination" I mean a policy that makes non-vaccination illegal for anyone for whom vaccination is not medically contraindicated, without any accommodation for conscientious objection. Since there will always be, in any given population, a certain percentage of people who cannot be vaccinated for medical reasons and who will contribute to lowering the vaccine coverage rate, realization of herd immunity might still require, in practice if not in principle, that all those who can be vaccinated without significant medical contraindication be vaccinated (Dawson 2007, p. 173). However, while these pragmatic considerations are certainly important when deciding which vaccination policy to implement, they are merely contingent and not principled reasons for unqualified compulsory vaccination: if the circumstances were 
such that we could be sure that enough people were vaccinated anyway, such pragmatic considerations would no longer apply. Since gathering data about vaccine coverage rate is routinely done by governments, it would not be very difficult to verify at any time whether aiming at universal vaccination coverage is necessary to at least realize herd immunity. Actually, the PLRA would demand to regularly verify such contingencies in order to implement, at any given time, the vaccination policy that is least restrictive of individual autonomy: according to the PLRA, there is an ethical imperative not to aim at universal vaccination coverage in order to realize herd immunity through coercive measures if less people can be coerced into vaccinating without threatening herd immunity. This requirement implies that we should switch from a more coercive to a less coercive policy when the more coercive policy is no longer necessary for the realization of herd immunity.

However, what I want to investigate here is whether there are principled, that is, ethical, reasons for unqualified compulsory vaccination. If they existed, such reasons would apply regardless of whether less restrictive measures for realizing herd immunity were available. This means that they would render irrelevant either the PLRA, for example, by claiming that, other things being equal, more restrictive policies can be justified, or the idea that herd immunity should be the goal of vaccination policies, for example, by claiming that vaccination policies should have more demanding targets. Here, I will pursue the second strategy: I will argue that vaccination policies ought to aim at universal vaccination coverage, rather than merely at herd immunity, and that therefore they ought to take the form of unqualified compulsion. This claim is consistent with the existence of the PLRA: I am not denying that less restrictive policies are ethically preferable to more restrictive ones, other things being equal. The point is rather that, so to speak, other things are not equal: as I shall argue, we ought not to choose the policy that is less restrictive among those that can achieve herd immunity, but we ought to choose the policy that is less restrictive and that would achieve universal vaccination coverage (where "universal" does not include, of course, individuals who cannot be vaccinated for medical reasons or for age limits). What is not equal is the appropriate aim of vaccination polices: not herd immunity - which is what was equal in the list of policies discussed in the previous chapter-but a fair distribution of the burdens entailed by herd immunity. That vaccination policies "ought to" aim at universal vaccination coverage means that the reasons for aiming at universal vaccination coverage are not merely pragmatic, but indeed ethical: there is an ethical principle that demands aiming for universal vaccination. 
In this chapter, I will argue that there are strong ethical reasons for enforcing compulsory vaccination, rather than less coercive vaccination policies, and for not allowing non-medical vaccination exemptions, and hence for enforcing unqualified compulsory vaccination. Of course, one might object that such ethical reasons would be worthless if it turned out that compulsory vaccination is less effective than other less coercive measures, that is, that vaccination coverage rates would (likely) be lower where compulsory vaccination is implemented. For example, one might suggest that compulsory vaccination could backfire by reinforcing people's antivaccination sentiments and by encouraging them to find ways to escape the requirement. After all, one might observe, given the importance of a good like herd immunity, we should prioritize effectiveness over other ethical values; or, put more sharply, a solution cannot be truly ethical if it prevents such an important public good as herd immunity from being realized. However, as I will argue below, even if it were true that compulsion would discourage people from vaccinating, compulsory vaccination would not backfire if adequately implemented.

\section{The Ethical Case for Compulsory Vaccination}

Claims to the effect that vaccination should be compulsory are typically grounded in considerations about the harm, or risk of harm, that nonvaccination presents to other people (e.g., Flanigan 2014; Bambery et al. 2013). Alternatively, they might appeal to the so-called clean hand principle (Brennan 2018), which morally prohibits people from becoming accomplices in the collective harm that would result from the failure to realize herd immunity. On yet other views, compulsory vaccination is justified by the fact that the state has an obligation "to guard the common good of herd immunity" in order to protect vulnerable people (Pierik 2016, p. 7). If you agree with my analysis of the relationship between individual and collective responsibility from Chap. 2, you will see that all of these justifications are problematic. As I have suggested, realization of herd immunity and therefore prevention of harm are collective enterprises: no individual can achieve these goals or make a significant contribution towards them. Since each individual contribution to the collective harm produced by low vaccination rates is negligible, and since each individual contribution to the "common good" (Pierik 2016) of herd immunity (which is more appropriately described as a "public good") is negligible, it is difficult to argue that each individual should be subject to a legal obligation to be 
vaccinated, as compulsory vaccination would require-at least if we accept the validity of the PLRA (which, as I have said, I have no intention to reject here). In fact, those who provide arguments for compulsory vaccination typically do not reject the PLRA as applied to policies aimed at minimizing risks, and indeed some of them explicitly endorse it. For instance, both Flanigan (2014, p. 20) and Pierik (2016, p. 8) state that vaccination policies aimed at protecting vulnerable individuals from risks of harm should be informed by the PLRA. Thus, their claims result much more attenuated than their initial intentions might suggest: ultimately, these arguments imply that vaccination should be compulsory only when there is some significant risk of harm posed by non-vaccination. In other words: an argument for compulsory vaccination would be very easily defeated by appealing to the PLRA as long as there are less coercive policies that could guarantee herd immunity. So considerations about harm to others cannot provide a principled justification for compulsory vaccination if we accept the PLRA, as I do here and as those who argue for coercive vaccination policies normally do.

According to Jason Brennan, the clean hand principle makes it impermissible even for libertarians to appeal to individual freedom against state-enforced vaccination, because in this case individual freedom would make one morally complicit in collective harm. But the clean hand principle is subject to the same objection about the relationship between collective and individual obligations: you cannot justify an individual obligation, a legal one in this case, to be vaccinated simply by appealing to the notion of collective harm. Even if you think, as a matter of private morality, that you should keep your hands clean and not make any contribution to some collective harm, you would need a more fundamental ethical principle to justify the enforcement, by the state, of a clean hand principle in case of insignificant individual contribution to collective harm. According to Brennan, the clean hand principle in the context of vaccination is an enforceable moral principle within a libertarian framework because it "stops individuals from causing harm" (Brennan 2018, p. 40). But this does not seem to be right: where there is a sufficiently high vaccination rate, getting my hands dirty - that is, refusing vaccination-does not cause any harm; and more generally, whether my hands are clean or dirty does not make a difference to whether herd immunity is realized. So why should I be required to keep my hands clean and contribute to the public good of herd immunity, if my contribution makes only a very small or even negligible difference to herd immunity? What is the political value or the impact on others of the mere fact that my hands 
are clean? Notice that I am not arguing here against Brennan's claim that vaccination should be compulsory, nor am I interested in how a libertarian could justify compulsory vaccination while remaining libertarian. Actually, I might even agree with Brennan's claim that "the libertarian must endorse something like the clean hands principle, and, further, must accept in some cases it is permissible to use coercion against the individuals who constitute the collective performing the rights violation or causing the harm" (Brennan 2018, p. 42). Whether I would be prepared to endorse this claim depends on how we interpret the phrase "something like the clean hands principle". This phrasing is quite vague. What does it mean? Something like, but not exactly, the clean hands principle? If so, I agree with this quite vague formulation, although it is not a very informative one; my point is simply that the "clean hand" principle itself (not "something like" it) does not do the work Brennan wants it to do.

One way to support the clean hand principle is simply dogmatic: keeping one's hands clean and not being moral accomplices of bad outcomes is good in and of itself, full stop. This is, for example, the approach that grounds the Catholic doctrine of the moral wrongness of formal cooperation in wrongdoing. Another possible approach could be considered deontological: getting one's hands dirty would violate some established ethical code. And there might be other ethical theories that can justify a moral obligation not to be accomplices in collective harms even when the individual contribution is negligible. Examples include contractualism (see, e.g., Giubilini et al. 2018), that is, roughly, the theory according to which we should act on the basis of principles that other people could not reasonably reject, or rule consequentialism, that is, the theory according to which everybody should follow those simple rules that, if followed by everyone else, would produce the best consequences, such as "be vaccinated". However, even if we want to accept any of these justifications (dogmatic, deontological, consequentialist, or contractualist) for the clean hand principle, they can hardly be taken to warrant the legal enforceability of a moral principle: some of them only concern the sphere of individual morality, and those that aim at informing policymaking (such as contractualism and perhaps some versions of rule consequentialism) require to commit to comprehensive moral theories that many people would not accept. In order to enforce a moral principle, the principle should ideally be one of those uncontroversially taken to have some relevance for policymaking, no matter what comprehensive moral theory one embraces. 
As it happens, there is one such ethical principle that does justify the legal enforceability of the clean hand principle and, more generally, that justifies an individual obligation - either moral or legal— to be vaccinated, starting from a collective obligation to realize herd immunity. This is, as I have argued in Chap. 2, a principle of fairness. For one thing, fairness is a principle that is typically taken to have relevance for policymaking: normally, we want public policies to be fair (the precise definition of which I will elaborate on later). Besides, unlike comprehensive moral theories such as contractualism or rule consequentialism, a principle of fairness is certainly widely shared and in line with commonly held moral intuitions: it is a principle most reasonable people would subscribe to when it comes to distribution of certain burdens, no matter what their ethical approach is. As such, it clearly qualifies as a reasonable principle-on any plausible understanding of "reasonable" - around which to design vaccination policies. Of course, the problem would be that of balancing it with other principles that reasonable people consider important as grounds for policymaking, such as individual liberty and maximization of expected utility (see, e.g., Selgelid 2009). As I will suggest in this chapter, even in light of this balancing, there are reasons to give fairness in the distribution of burdens priority over individual liberties in the formulation of vaccination polices and therefore to subject everyone to a legal obligation to be vaccinated in spite of the infringement on individual liberty.

John Stuart Mill is one of the champions of liberalism; he famously grounded the justification for coercive state interventions on the so-called harm principle-roughly, the principle that the only purpose for which states may and ought to use its coercive power is to protect individuals from liberty restrictions or harm caused by other individuals' behaviour. But even Mill at some point had to introduce considerations of fairness to justify the legal enforceability of individual moral obligations in the context of prevention of collective harm. Even in his view, appeal to harm prevention was not sufficient to ground certain individual moral and legal obligations in those cases where some individual contribution to a collective harm-or to the failure to realize a collective benefit—would be negligible or in any case would not determine whether other people would be harmed. Instead, he formulated the following principle, which clearly refers to fairness requirements:

everyone who receives the protection of society owes a return for the benefit, and the fact of living in society renders it indispensable that each should be found to observe a certain line of conduct towards the rest. This conduct 
consists $(\ldots)$ in each person's bearing his share $(\ldots)$ of the labours and sacrifices incurred for defending the society or its members from injury and molestation. (Mill 1859, pp. 140-141)

This principle could ground a legal obligation for each citizen to vaccinate themselves or their children, as an instance of a more general obligation to fairly contribute to important public goods (as people normally do, for example, through taxation.). Granted, the notion of fairness involved in Mill's formulation is different from the notion of fairness I have defended in Chap. 2: while Mill seems to appeal to a principle of reciprocity and to a duty not to free-ride, my argument in Chap. 2 referred to fairness in the distribution of the burdens entailed by the collective obligation to realize herd immunity. But the important point I want to emphasize here is that, even within Mill's perspective, a mere reference to prevention of harm to others is not sufficient to justify individual moral or legal obligations.

Before I proceed, it is worth clarifying that there are different ways of understanding "fairness". Perhaps the most fundamental distinction is between fairness as equity and fairness as equality. The former implies that a fair distribution of burdens is one where everyone is burdened according to some morally relevant criterion, such as her capacity to bear the burden, or considerations of desert or lack thereof. The latter implies that a fair distribution is one where everyone is burdened the same, regardless of capacities or of any other factor. In Chap. 2 I assumed that a fair distribution of the burdens of the collective responsibility to realize herd immunity was one where everybody without medical contraindications against vaccination be vaccinated. In light of the distinction I have just drawn, this represents an equitable, not an equal distribution of the burdens: those who do not have the capacity to bear the burden of vaccination are not subject to the fairness-based obligation to be vaccinated. In general, the same principle of fairness as equity applies when it comes to policymaking regulating any distribution of burdens. Fairness as equity, for example, is the reason why taxation as a form of contribution to public goods is often progressive, rather than proportional or flat: people are not subject to the same tax rate, but are taxed in consideration of their capacity to contribute to state expenditures, for instance, on the basis of factors such as income, number of dependants, number of houses owned, and so on. The same criterion should be applied-or so I have argued - to the case of vaccination as a contribution to herd immunity, except that, in the case of vaccination, there are only two options: either one contributes by being 
vaccinated, or one does not contribute by being exempted for medical reasons, that is, because one does not have the capacity to contribute in the same sense in which others have such capacity.

Thus, fairness is an important ethical and social value when it comes to sharing burdens required by the preservation of public goods. In the remainder of this section, I will explain in what sense fairness is an important ethical value; this explanation will clarify why fairness is not in conflict with the PLRA, when the PLRA is properly understood in the context of vaccination policies. In the next section, I will explain in what sense fairness is an important social value; this explanation will clarify why fairness is not in conflict with a principle of maximization of expected utility (which might seem obvious, but which some people have questioned).

Now, as for its ethical aspect, I have said that there are reasons to prioritize fairness in the distribution of burdens over individual liberty in the formulation of vaccination policies. In other words, from an ethical point of view, fairness trumps liberty in the context of vaccination policies. Admittedly, the claim is controversial: Nozickian libertarians, for example, would claim that bodily autonomy is a fundamental liberty, and therefore the state is not justified in violating bodily autonomy to promote a good that is valuable for the community (for a discussion, see Navin 2015, p. 182). However, one might argue that there are reasons to reject this implication within a libertarian framework even if, as I have suggested above, we have reasons to reject Brennan's appeal to the "clean hand" principle. As suggested by Navin, within a libertarian framework, the state is still justified in implementing coercive policies that infringe upon certain individual rights if such policies are necessary to prevent harm to others, because harm to others-for example, in the form of infectious diseasesdoes limit their liberty (Navin 2015, p. 182). But Navin's argument is problematic: if my non-vaccination does not significantly increase the risk posed on others, especially when vaccination coverage is very high, how can libertarians consistently justify coercive vaccination policy, given that my non-vaccination would not significantly threaten other people's liberty? The answer is that they cannot without also accepting that, in the case of collective harm, the harm principle does come with a fairness principle attached, as a matter of basic ethical requirement. Some libertarians might not accept that fairness plays this important role in policymaking-though rejecting a fairness requirement would make it difficult to accept "something like" the clean hand principle. But their refusal to accept the fairness requirement in policymaking tells more about the low ethical standard 
libertarians apply to policymaking than about the importance of the fairness requirement in the distribution of burdens entailed by public goods.

Moreover, it might be argued, even libertarians would concur that a state should ensure that individuals make a fair contribution to the prevention of such harm. Mark Navin, for example, has defended a principle of fair distribution of certain burdens from within a libertarian perspective-although he is not a libertarian - by way of analogy with other cases where he thinks at least certain libertarians do endorse such principles of fairness. For example, Navin argues, libertarians would agree that the state is justified in ensuring that everybody pays their fair share of taxes to support military and police expenditures, in order to protect national security and public safety, which are necessary for protecting individual liberty. And as we have said above, fairness is also what ultimately justifies the "clean hand" principle that some libertarians want to incorporate within their ethical perspective to justify coercive vaccination policies. Thus, even within a libertarian framework, it can be argued that fairness does play a fundamental role in determining how the burdens entailed by the preservation of certain goods and prevention of certain harms should be distributed (Navin 2015, p. 182).

So far, I have established, at the very least, that fairness in the distribution of the burdens entailed by the preservation of public goods (or, in a libertarian framework, of those goods that prevent serious harm to individuals and thus compromise their liberty) is an important value in the formulation of public policies, and of vaccination policies in particular. However, I want to argue for something stronger: my claim is that fairness is a value that need not and should not be compromised by being balanced against other values involved in policymaking, such as individual liberty and expected utility (i.e., the realization of herd immunity).

With regard to the three core ethical values informing reasonable public policies, it would seem that the relevant question is: what is the relative importance of fairness, expected utility, and liberty in the formulation of public policies aimed at realizing herd immunity? More precisely, if this is the relevant kind of question, it would seem that at this stage of my argumentation the actual question should be restricted to the relative weight of fairness and the PLRA and to the relative weight of fairness and expected utility. After all, we already know how to balance liberty and expected utility: we have already established that one of the goals of vaccination policies is the realization of herd immunity, and that balancing the value of expected utility against the value of individual liberty leads to the reformulation of a principle of liberty in terms of the PLRA: we ought to implement the least 
restrictive policy that is effective in realizing herd immunity. So what remains to be done is to establish how to balance fairness against the PLRA and fairness against expected utility. The relevant question seems, then, to be the following: provided that we ought to realize herd immunity, how should we weigh fairness in the distribution of burdens entailed by the realization of herd immunity against the PLRA and fairness against expected utility?

I want to claim is that this is not the right question to ask. The more fundamental, and more important, questions are rather the following: is fairness really in conflict with the PLRA, understood as a principle protecting individual liberty? Or, is fairness really in conflict with expected utility, understood as the realization of herd immunity, in the formulation and implementation of vaccination policies? If the answer to both questions were negative, then the questions about the relative importance of fairness and the PLRA and about the relative importance of fairness and expected utility would not arise at all, because we would not need to balance them one against the other. And indeed, the reason why I claim that fairness "need not" and "should not" be balanced against other values is that there is no actual conflict between fairness and the PLRA and between fairness and expected utility.

Now, I am of course aware that, at a first glance, it would seem that fairness and the PLRA are in conflict with one another, and therefore that if compulsory vaccination were enforced on the model of compulsory taxation to ensure that everybody made their fair contribution to the public good, the PLRA would automatically be violated: after all, herd immunity could be realized even with policies that would allow some people to obtain non-medical exemptions or that would simply nudge or incentivize people to vaccinate. Therefore, the PLRA, to the extent that it requires implementing non-compulsory policies whenever non-compulsory policies are consistent with the realization of herd immunity, means that fairness is violated in principle - although it might still be realized in practice in the extremely unlikely event that everyone decided to be vaccinated or to vaccinate their children even when they are not be compelled to do so. Even Mark Navin, one of the advocates of the importance of fairness in the current debate on vaccination policies, thinks that fairness needs to be balanced against something like the PLRA when it comes to vaccination policies, and therefore that, in spite of the fairness requirement, compulsory vaccination should not be enforced when less restrictive policies are 
effective in realizing herd immunity. As Navin writes, "the state has the authority to coerce vaccination, though there are good reasons for it to use as little coercion as is necessary to achieve the goal of herd immunity" (Navin 2015, p. 12); elsewhere, as we will see below, he argues that nonmedical exemptions to vaccination mandates should be allowed as long as herd immunity is realized, in order to preserve liberty to the greatest extent possible (Navin and Largent 2017).

However, the conflict between fairness and the PLRA is only apparent. The analogy between vaccination policies and taxation policies is a very good one, because it shows that when we need to ensure that important public goods are preserved or realized, as is the case with taxation, the appropriate goal to pursue is not only the realization or preservation of such public goods but also that everybody makes their fair contribution to them. As we have seen in Chap. 1, (1) everybody benefits from public goods and from herd immunity in particular, and, as we have seen in Chap. 2, (2) we do have a collective obligation to realize herd immunity, and the vast majority of us has the capacity to make our contribution to the fulfilment of this collective obligation at a small personal cost. Therefore, it would be unethical for a policy to aim at the realization of herd immunity without considering the fairness implications of (1) and (2): everybody ought to contribute to herd immunity (1) as a matter of reciprocity and avoid free-riding and (2) as a matter of fair distribution of burdens. To compare, people are normally not exempted from paying their share of taxes just because they do not ethically approve of some ways in which their government spends public money, such as in the case of pacifists, or because they are afraid that it would be unsafe to spend public money in certain ways, for example, in case someone thought that some military operations would trigger reactions from terrorists in one's own country. These exemptions would simply be unfair, given that, for instance, even pacifists benefit from the public good of national security preserved through military forces (reciprocity and freeriding consideration) and that also pacifists are able to contribute to the fulfilment of the collective obligation to preserve national security (consideration of the distribution of burdens). ${ }^{1}$ Thus, fairness is not simply

\footnotetext{
${ }^{1}$ I am assuming here that there is such a collective obligation; if you think that there is not, you can replace the national security example with the example of any other important public good that you think we have a collective obligation to preserve, such as clean air or a publicly funded health system.
} 
one of the principles informing public policies aimed at regulating the distribution of burdens entailed by realization or maintenance of certain public goods but actually one of the goals of such policies. Fairness and the PLRA are not in conflict with one another because in the context of policies aimed at preserving important public goods they are not on the same level of importance, and actually the attempt to balance them against one another presupposes a categorical mistake: fairness is one of the ends of vaccination policies, while the PLRA is a way of determining which means are appropriate to the ends. That fairness is "one of the ends" of vaccination policies does not mean, of course, that fairness is as important a goal as other goals of vaccination policies and in particular the protection of population's health; but it does mean that it is something vaccination policies should aim at in pursuing their more fundamental goal. We can think of fairness as a subordinate or secondary goal of vaccination policies: we do not enforce vaccination policies in order to promote fairness, but once we decide to enforce vaccination policies in order to realize herd immunity and prevent harm, fairness does become one of the goals of these policies, because herd immunity should be realized fairly. What constitutes the "least restrictive alternative" depends on the ends that a policy is supposed to promote (for instance, the least restrictive policy that is able to realize herd immunity), but fairness is itself one of the ends that a policy aimed at protecting or realizing an important public good should promote, together with its more fundamental goal of realizing the public good in question. In other words, a successful vaccination policy is not only one that achieves herd immunity but one that achieves herd immunity fairly. Of course, once we have established that the goal is a fair realization of herd immunity, we still need to apply the PLRA and try to achieve the goal through the least restrictive policy possible; but we need not and indeed should not reach a compromise between the ends and the ethical restrictions about which means should be used to achieve those ends. Doing that would undermine the very purpose of the policy. Unfortunately, in practice, the least restrictive policy that would allow to fairly realize or preserve herd immunity is very likely to be unqualified compulsory vaccination, in the same way as unqualified compulsory taxation is very likely to be the least restrictive policy that can ensure that everybody makes their fair economic contribution to certain public goods. Many people would not vaccinate and would not pay their taxes if they were not compelled. True, compulsory vaccination also happens to be a very restrictive policy, but this does not mean that it violates the PLRA; it 
only means that, given the legitimate ends of vaccination policy, the PLRA has limited scope for influencing the level of restrictiveness of the policy.

One might observe at this point that, even with compulsion, some people would still be able to get away with refusing vaccination in the same way as some people manage to evade taxes and go unpunished. Therefore, my argument seems to involve a reductio ad absurdum because it seems to entail that, in order to fulfil the requirements of both fairness and expected utility, even more restrictive policies would be required, such as forced vaccination-for example, with health and if necessary police authorities visiting individual households and performing the inoculation. But clearly, forced vaccination is unacceptable, or at least so the objection might go (and I shall assume, for the sake of argument, that this is true). Thus, since my argument has an unacceptable implication, some of its premises (e.g., about the importance of fairness) or something in its logical steps (e.g., the analogy with taxation), or both, must be wrong. However, I am not arguing for forced vaccination here, and I do not think that my argument would commit me to endorsing forced vaccination. Therefore, I do not think that the argument leads to a reductio ad absurdum.

Why do I say that my argument does not imply a defence of forced vaccination? The reason is not, as many might be thinking, that forced vaccination would violate a principle of bodily integrity or bodily autonomy and therefore that such principles would morally outweigh the moral force of fairness when it comes to forced vaccination. The principles of bodily integrity or bodily autonomy need to be properly understood and, I would add, properly downplayed.

For one thing, bodily autonomy and bodily integrity are only prima facie principles that can permissibly be violated, and indeed are often violated, when something more valuable has to be promoted, and effectiveness and fairness in vaccination policies are very important values. Thus, for example, sometimes forced medical treatments are carried out in spite of the violation of bodily integrity and bodily autonomy-such as in the case of people with certain mental disorders or in the case of chemical castration for some sex offenders in certain states, such as currently California or Indonesia; and sometimes other equally restrictive measures are forced upon individuals to protect public health-such as in the case of quarantine or isolation to prevent or contain epidemics. For another thing, we should not and normally do not attribute such a great importance to the principle of bodily integrity or bodily autonomy; for example, most of 
us are fine with fluoride being added to running water, often without people being adequately notified about it, for the sake of individual and public health (specifically, preventing tooth decay). However, people who are opposed to vaccines and who appeal to principles like bodily integrity and bodily autonomy are unlikely to accept the hypothetical administration of vaccines through the same means, for example, if, as a thought experiment, vaccines could simply be added to running water. This suggests that the real (ethical) concern is not about violation of bodily integrity or autonomy, but specifically about vaccines.

Thus, the reason why my argument does not lead to a defence of forced vaccination has nothing to do with a principle of bodily integrity or bodily autonomy - and after all, even compulsory vaccination would be inconsistent with a principle of bodily integrity or autonomy. Rather, I "only" argue for compulsory vaccination because I am interested in the ethical principles involved in vaccination policies and their relative priority: expected utility, fairness, and PLRA. An adequately implemented compulsory vaccination policy would meet all the requirements set by these principles, without having to implement even more restrictive policies.

Thus, in an ideal world where everyone abides by the law, compulsory vaccination satisfies all the ethical principles of policymaking. True, in the real world many people do not observe the law and many of them get away with it. Therefore, likely, no compulsory policy would achieve a $100 \%$ observance, thus falling short of meeting the requirements of fairness in the distribution of burdens. If someone thinks that this empirical consideration justifies the implementation of forced vaccination, I would not think that their point of view is obviously unacceptable. The issue at stake is whether in-principle considerations should be replaced by more down-to-earth practical considerations when formulating public policies; but this is an issue I am happy to leave open here. I will only note that if we had to replace in-principle considerations with more practical considerations, then we might as well sacrifice the principle of fairness and implement less restrictive policies that would allow a few people to unfairly free-ride on herd immunity as long as herd immunity is not threatened, and this approach would a fortiori rule out any justification for forced vaccination. But I think that a public policy should take important ethical principles into account.

So far, I have argued that fairness is not in conflict with the PLRA because the two principles are not on the same level, and therefore that compulsory vaccination is ethically justified because it promotes fairness 
without violating the PLRA. What about the second possible conflict between the values at stake in vaccination policies, namely, that between fairness and expected utility? I will address this question in the next section.

\section{The Social Relevance of Fairness}

The second aspect of fairness that I have mentioned above, namely, its social relevance, is what explains why fairness and maximization of expected utility are not in conflict with each other. Fairness in the distribution of burdens entailed by public goods has social relevance in the sense that it can influence people's behaviour in such a way as to determine whether or not socially important public goods become realized. Not only, as we have seen, maximizing expected utility by ensuring that as many people as possible are vaccinated promotes fairness; also, promoting fairness in the distribution of burdens entailed by the fulfilment of collective obligations is likely to contribute to the fulfilment of the collective obligation. How so? Because fairness is also likely to be instrumentally valuable: knowing that the burdens to which they are subjected are fairly distributed among people around them provides individuals with additional motivation to choose to bear their share of the burden, or at least removes some psychological barriers to cooperation. In other words, ensuring a fair distribution of the burdens of herd immunity would solve the so-called problem of assurance (Navin 2015, pp. 179-180), which Rawls identified as deriving from the fact that people would presumably be willing to contribute their fair share to a public good only if they knew that others are doing the same (Rawls 1971/1999, p. 236). Therefore, aiming at a fair distribution of burdens makes it more likely that the objective in question-in our case the realization of herd immunity-is achieved. The instrumental value of fairness might partially address the concern discussed above that even with compulsory vaccination some people would still be able to get away with nonvaccination: a fair distribution of the burdens of vaccination would ensure that free-riders are not as plentiful as they would otherwise be.

These claims about the social relevance of fairness are supported by a body of psychological evidence and evidence from neuroscience, including functional magnetic resonance imaging ( $\mathrm{MMRI}$ ), suggesting that being treated fairly is associated with positive emotions that motivate people to cooperate in collective enterprises, while unfairness produces the exact opposite consequences (see, e.g., Tabibnia et al. 2008). Cooperation is 
understood in the context of such psychological studies as "doing one's share to maximize public goods rather than working individually to maximize personal goods" (Tabibnia and Lieberman 2007, p. 91), a definition which fits well with what I have argued is an individual moral obligation in the case of vaccination (except that in many cases vaccination would also maximize an individual's personal good). Fairness in the distribution of rewards, burdens, and obligations is a powerful motivator to act cooperatively towards common goods (Tabibnia and Lieberman 2007): we know that humans tend to contribute to common objectives when they know that there are fair arrangements in place, but, despite the desirability of the common objective, they tend not to make their contribution under unfair arrangements. For instance, experiments in the context of the "Ultimatum Game" have shown that people are less likely to collaborate in order to achieve a common good if they perceive they have been treated unfairly. In the standard Ultimatum Game, one player, the proposer, is asked to split a sum of money with another player, the responder; the proposer can decide in what proportion (e.g., $80 / 20$, or $50 / 50$, etc.) to split a sum of money, and the responder can decide whether to accept or reject the offer; if the responder rejects the offer, neither player gets anything, whereas if the responder accepts, each one gets the sum that has been decided by the proposer. In spite of the financial gain in accepting an unfair offer, a perceived unfair offer of $20 \%$ of the sum-as opposed to a perceived fair offer represented by an equal share-has a $50 \%$ chance of being rejected by the responder, even if this means her losing out on that $20 \%$; simply, the emotional reaction of the responder is to punish the proposer for the unfair treatment even at a personal and at a collective cost (Guth et al. 1982; Camerer and Thaler 1995). In other words, people fail to collaborate towards a common good-in this case, represented by retaining the sum of money, even if unfairly split-if they perceive others are not acting fairly towards them. In fact, studies have shown "neural overlap between the pleasure of being treated fairly and that associated with the intention to cooperate", as well as a decrease of such brain activity in cases of unreciprocated cooperation (Tabibnia and Lieberman 2007, p. 96). It is not unreasonable, and indeed it seems to me quite plausible, to suppose that the same psychological mechanisms are triggered when fairness issues arise in the context of individual contributions to herd immunity.

Thus, these studies suggest that fairness does contribute towards the maximization of expected utility by solving the problem of assurance. But on what basis, then, would anyone think that compulsory vaccination 
might undermine the expected utility of vaccination policies, if by promoting fairness it gives people motivation to contribute towards the realization of herd immunity? Some authoritative experts in the fields of vaccines and vaccination policies have claimed that coercive vaccination policies could backfire (Nature editorial 2018), for example, by undermining people's motivation to vaccinate. However, there is no evidence that current coercive vaccination policies have this effect. For example, when the Italian government introduced vaccination as a requirement for enrolling young children in childcare and primary school, as well as compulsory vaccination for school-age children, child vaccination uptake significantly increased in 2017, within just one year of the policy's introduction. For children born in 2015, MMR vaccine uptake increased by $4.42 \%$ (from about $87 \%$ to about $92 \%$ ) and the 6 -in-1 vaccine uptake increased from about $93 \%$ to about $94.5 \%$, allowing to reach the threshold of herd immunity in 11 of the 20 Italian regions. For children born in 2014 , the coverage rate of the 6 -in- 1 vaccine increased from about $93 \%$ to about $95 \%$, and the MMR vaccine coverage rate had an astonishing increase of more than $5 \%$, from about $87 \%$ to about $92 \%$ (all the data are available from Italian Ministry of Health 2018). It might be too early to draw any definitive conclusion about the effectiveness of such coercive policies: the trend in the next years might be the same as the trend in the last year, or it might be the exact opposite. And the effectiveness of compulsory vaccination might turn out to be a short-run phenomenon, as can sometimes be the case with mandatory vaccination (as we have seen in Chap. 3). Time will tell. Also, of course, it might well be that in some other places a compulsory vaccination policy like the one implemented in Italy, with a 500 euro fine for non-vaccination, would actually backfire. But whether and for how long compulsory vaccination would be effective is more likely to depend on the magnitude of the legal penalty and on the way it is implemented than on the element of compulsion itself. Even if a certain coercive vaccination policy, and compulsory vaccination in particular, were to somehow backfire, this would hardly be an argument against coercion or compulsion. Instead, it would be an argument in favour of enhancing controls on compliance with the legal requirement and on increasing the penalty for non-vaccination in order to contrast the potential backfiring effect. No matter how strongly opposed to vaccination a person is, there will always be a penalty they are not prepared to pay for non-vaccination. And the same consideration applies in the case of people who do not vaccinate out of concerns about safety and effectiveness of vaccines. 
This is not to say that we should not try to address people's concerns about vaccines through other policies, such as appropriate information campaigns or strategies aimed at promoting trust between doctors and citizens. Of course, compulsory vaccination would have to be accompanied by policies aimed at increasing people's confidence in vaccines, so that they would be more likely to comply with legal requirements. But we do need to ensure that everybody contributes their fair share to the achievement of the preservation of the public good of herd immunity; and to this end, compulsory vaccination is the ethically acceptable and indeed ethically obligatory policy measure to adopt. It is ethically acceptable because it only compels individuals to fulfil an ethical obligation they independently have (as discussed in Chap. 2), and not to do something supererogatory or beyond the "call of duty". And it is ethically obligatory because fairness itself ought to be an aim of vaccination policies, and fairness demands that everybody take on themselves an equal share of the burdens entailed by the realization of herd immunity; it is unlikely that anything less than compulsion would get closer to this goal. At the same time, compulsory vaccination also fulfils the ethical requirements of expected utility, of fairness, and of the least restrictive alternative.

Let us briefly review in what ways the ethical case for compulsory vaccination complies with the three fundamental ethical requirements of public policies. As for expected utility, compulsory vaccination is likely to be highly effective at achieving the stated goal, in that it would allow for the highest possible vaccination rates compared to any other policy (with the exception of forced vaccination), provided the legal penalty is sufficiently burdensome and adequately implemented. As for fairness, compulsory vaccination would distribute the burdens of such collective enterprise in the fairest possible way, again with the exception of forced vaccination. As for liberty, compulsory vaccination does not infringe on any liberty right not to be vaccinated, because such rights do not exist in this context.

One might reasonably observe that there is a difference between adult and child vaccination. For instance, parents do pay taxes and thus make personal sacrifices for the sake of the collective good, but children are obviously not required to make an equivalent contribution, given that they do not have the resources or the capacities to do it (indeed, they are on the receiving, as opposed to contributing, end of important goods). So how do the requirements of fairness, according to which each individual ought to make their fair contribution to herd immunity, apply to children? We obviously do not expect those who do not have the resources or the capacities - such as children, but also those who live in extreme poverty- to 
make their contribution to public goods through taxation. The legal obligation to make one's contribution obviously presupposes the capacity to make one's contribution, and children, as well as other groups, often lack these capacities. But the case of vaccination is different. Since children do have the capacity to make their contribution by being vaccinated, assuming that vaccination does not pose any significant cost on them, it follows that they should be subject to the same legal obligation. It might be more problematic to say that they have a moral obligation, since on many plausible accounts of moral responsibility, being an autonomous agent is a necessary for condition for being subjects of moral responsibility, and very young children do not count as autonomous agents. But if, as we saw in Chap. 2, the moral responsibility is supposed to fall on parents, who make choices on behalf of their children, then the fact that children cannot have moral obligations does not pose any problem; ultimately, it is parents who have both the moral and the legal responsibility to vaccinate their children.

\section{On Non-Medical EXemptions From COMPUlsory VACCINATION}

What I have said so fair about the fairness-based moral obligation to vaccinate oneself or one's children, and about the fairness-based justification for compulsory vaccination policies, has implications for the issue of conscientious objection to vaccination. Non-medical vaccine exemptions to vaccination mandates are granted in most-though not all-US states, where vaccination is mandatory for enrolling children in school. It is not surprising that, within the debate on the ethics of vaccination and of vaccination policy, conscientious objection to vaccination has received quite a lot attention in the last few years (see, e.g., Clarke et al. 2017; Navin and Largent 2017; Giubilini et al. 2017). After all, within medical ethics more broadly, conscientious objection and appeals to "conscience" have become the standard way of claiming an alleged right to stick to one's own allegedly ethical preferences where one would normally be required-either by professional or legal obligations, or both-to do otherwise. Appeals to conscience are often deployed to suggest the idea that there can be reasonable moral disagreement about certain issues and that, in virtue of this reasonable moral disagreement, people should be free to follow their conscience. Conscience is like a magic word that confers unwarranted authority to any view or idea one might hold (Giubilini 2016). 
Conscientious objection to vaccination is regulated differently in different US states. (It is worth noting that, in the context of US policy, we are talking about exemption to mandatory rather than to compulsory vaccination, but the same ethical considerations apply.) Sometimes non-medical exemptions are granted only for religious reasons, but not for other kinds of personal reasons. This is currently the case in 29 US states; Vermont in 2016 was the last state, in chronological order, to implement what Navin and Largent have dubbed the "prioritizing religion" model (Navin and Largent 2017). This model, however, is marred by a number of grave practical and ethical shortcomings: not only is it very difficult to define what counts as "religious" and to assess whether people's views are religious, but more importantly, when it comes to protecting individual liberties, privileging religion over other views fails to promote that minimum level of neutrality among different conceptions of the good that liberal societies are supposed to promote (Navin and Largent 2017). Hence, I will refrain from any further discussion of this model.

There are different possible views on how conscientious objection to vaccination, whether compulsory or mandatory, should be regulated. Some have observed that in the same way as conscientious objection is normally granted in other contexts on the basis of deeply held ethical or religious views, for example, in the case of pacifists' exemptions from conscription, so those with ethical or religious beliefs against vaccination ought to be exempted from vaccination mandates, provided there is no significant risk for third parties (Navin and Largent 2017). In order to keep the number of conscientious objections to a minimum, and thus ensure that herd immunity is realized while individual freedom remains reasonably protected, Navin and Largent have endorsed what they call the "inconvenience" model, as recently implemented, for example, in Michigan: in brief, parents applying for non-medical exemptions to vaccination mandates are required to go through some burdensome and inconvenient procedures, including not only bureaucratic procedures but also things like attending immunization education sessions. In this way, only those who have genuine ethical or religious objections to vaccines are likely to be willing to go through such procedures, and therefore this model is likely to strike a reasonable balance between protection of individual freedom (of those with genuine ethical or religious objection to vaccines) and effectiveness in reaching sufficiently high vaccination rates. And in fact, there is evidence in support of Navin and Largent's point, since burdensome exemption rates have been shown to lower exemption 
requests (Blank et al. 2013; Omer et al. 2012; Rota et al. 2001). For example, in Michigan, one year after the implementation of the inconvenience model in 2106, exemption rates fell by $39 \%$ (and by $60 \%$ in the Detroit area) (Higgins 2016; Navin and Largent 2017).

A second approach is slightly less favourable to considerations of individual liberty, but still aims to strike a balance between liberty, effectiveness of vaccination policies, and fairness. According to this approach, individuals who are exempted from vaccination mandates should be required to compensate society for their failure to contribute to herd immunity. In this way, people would still be free to refuse vaccination, but they would be discouraged from doing so, and would have to pay a price if they did refuse. There are two ways of understanding this requirement. Both interpretations are based on a comparison between conscientious objection to vaccination and conscientious objection to the military service. According to one version of this view, as we saw in Chap. 3, individuals who refuse vaccination should be required to make an alternative contribution to society in the form of a tax, in lieu of their contribution to herd immunity through vaccination. The size of this alternative contribution should depend on the extent to which non-vaccination is likely to harm others, which in turn depends on factors such as the severity and morbidity of the disease in question (Clarke et al. 2017). However, while this approach points in the right direction by giving some weight to considerations of fairness, there are two problems with it. The first is that any case of non-vaccination is unlikely to harm others where herd immunity exists, and therefore people would be required to make an alternative contribution only where vaccination rates are low, which would contradict a requirement of fairness. Second, people who are exempted from military service are typically not taxed, but are required to make an alternative contribution to society. But a tax in this context would look a lot like a financial penalty, rather than an alternative contribution. Overall, the problem with this approach is that, while it is similar to my suggested model of compulsory vaccination in that it proposes a financial penalty for non-vaccination, it only applies this tax/penalty in proportion to the actual risk posed by non-vaccination. The implication is that if the risk is negligible, vaccine refusers could simply get away with non-vaccination and free-ride on herd immunity, failing to make their fair contribution to the fulfilment of the collective obligation to realize herd immunity. 
In order to fulfil a requirement of fairness and to be consistent with other cases of conscientious objection (in particular towards military service), we might envision a second variant of the same approach, wherein those who refuse vaccination should make some alternative contribution to society-one that is independent of the actual risk that a specific case of non-vaccination poses on others and that is roughly equivalent to the contribution one would make to public health by being vaccinated. For example, in the same way as those who refuse to enrol in the military are typically required to provide alternative social services (such as working in public libraries, assisting with provision of services for people with disabilities, etc.), people who refuse vaccination could be required to make some alternative contribution to public health, such as preparing healthy meals for children at school or participating in fundraising activities in support of infectious disease research. This is what has been called the "contribution model" for non-medical vaccine exemptions (Giubilini et al. 2017): the point here is that those who refuse vaccination should not be "punished", but rather required to make their fair contribution to the public good in question, or to a roughly equivalent good, in other ways. While this model of dealing with vaccine refusal is preferable to the ones described so far in that it goes further than the alternative ones in promoting liberty, expected utility, and fairness, it does have its own shortcomings. For how are we to determine this rough equivalence? The problem is that the rough equivalence between the two types of contribution cannot be measured in terms of the actual impact of individual behaviour on the good in question, since in either case such contribution is likely to be negligible. So the equivalence needs to be measured in terms of the societal benefit of the (public) goods to which one is required to contribute. But the problem is that the alternative public health goods contemplated by the contribution model are not really commensurable with herd immunity: herd immunity is very likely to prevent illness and even death from vaccine-preventable infectious diseases, an outcome that would be extremely beneficial to many individuals and to society. The goods promoted by the other suggested contributions to public health are either less beneficial (such as giving children healthy food) or of more uncertain and of longer-term realization (funding research to find cures for dangerous infectious diseases). What we want when implementing vaccination policies is the realization of herd immunity through a fair distribution of the burdens entailed by herd immunity itself. None of the alternative contributions proposed would go in this direction. Therefore, none of the alternatives would promote fair distribution of the burdens 
entailed by the realization of herd immunity, although they would promote some form of fairness.

On the basis of the argument provided in this chapter, it should be apparent to those who agree with it that the problem with all these proposals is that, even if they are consistent with or would promote the realization of herd immunity, they assume that herd immunity is the only legitimate aim of vaccination policies. In other words, they disregard the fundamental value of fairness as an end in itself of morally acceptable policies aimed at protecting important public goods, which I have defended in this chapter. Simply put, and as an obvious implication of my argument in this book, fairness in the distribution of the burdens of herd immunity is itself an end of vaccination policies, and therefore granting some people non-medical exemptions would violate the fairness requirement.

But what about the analogy with conscientious objection to conscription? After all, one might insist, if we accept that pacifists should be exempted from contributing to a public good like national security-and that they should at most be required to provide some alternative service to society - why should we not adopt the same type of exemption policy in the case of vaccination requirements? I offer two very short answers to this reasonable observation. First, the analogy with conscientious objection to military service is just one possible analogy. An alternative analogy-the one on which I have sometimes relied on here-is the one with taxation. In the case of taxation, exemptions are normally not granted, not even by requesting individuals to make alternative contributions instead. If someone thinks that the choice between the two analogies is merely arbitrary, and therefore that there are no particular reasons for preferring the taxation analogy over the military analogy, they would have to acknowledge that there are no particular reasons for preferring the military analogy over the taxation analogy either; therefore, the taxation analogy is not inferior to the military analogy, and my preference for the analogy with the taxation model cannot really be criticized. Second, not only is the taxation analogy not inferior to the military analogy, but, I would argue, it is actually preferable: requesting each person to pay their fair share of taxes would ensure that certain public goods are realized through a fair distribution of the burdens they entail—which, as I have argued in this chapter, should be the final aim of ethically acceptable vaccination policies; on the contrary, allowing conscientious objection in the military context would not guarantee that the public good of national defence is realized fairly. 
But does then my argument imply that conscientious objection to conscription is also ethically wrong and that for the sake of fairness pacifists should be forced to enrol in the military where conscription is in place? And would I be prepared to accept this implication in order to defend my argument for compulsory vaccination without the possibility of nonmedical exemptions? As unappealing and perhaps counterintuitive as this position might sound, the argument I have developed in this chapter, and indeed throughout the entire book, compels me to give an affirmative answer to both questions. I am happy to accept this implication. There should be compulsory vaccination policies in place that do not allow for any non-medical exemptions, and there should be no conscience-based exemption to conscription, at least if we agree that national defence should be guaranteed also through conscription and not only through professional soldiers; if we thought that national defence ought to be protected only by professionals in the military, the analogy with vaccination would not apply, since there is no equivalent profession in the case of vaccination (not least because we would need to pay a huge number of "professionals" to achieve herd immunity, way more than those required for national security).

\section{Conclusion}

As I have argued in this book, an ethical approach to vaccination choices and to vaccination policy supports the following claims:

1. There is a collective responsibility, or collective moral obligation, to realize herd immunity.

2. There is an individual moral obligation to contribute to the realization of herd immunity by being vaccinated or by vaccinating one's children.

3. The state has an institutional responsibility to implement vaccination policies that can guarantee at least the realization of herd immunity.

4. If the aim of vaccination policies were merely the realization of herd immunity, then a principle of least restrictive alternative would imply that the state has an institutional responsibility to implement the least restrictive policy that would be effective in achieving this goal.

5. However, a principle of fairness requires that everybody - not just the smallest number of people that can realize herd immunity-makes their fair contribution to herd immunity by getting vaccinated. 
6. The existence of an individual obligation to be vaccinated or to vaccinate one's children implies that the state is morally justified in requiring each individual to be vaccinated or to vaccinate their children, in the absence of legitimate medical reasons for exemptions; in other words, compulsory vaccination without non-medical exemptions is ethically justified.

7. A principle of fairness in the distribution of the burdens entailed by an important public good like herd immunity implies that the state ought to require each individual to be vaccinated or to vaccinate their children, in the absence of legitimate medical reasons for exemptions; in other words, enforcing compulsory vaccination without non-medical exemptions is an ethical obligation of states.

8. Compulsory vaccination meets the requirements posed by the ethical principles that should inform policymaking, namely, maximization of expected utility, fairness, and least restrictive alternative, if properly understood.

\section{REFERENCES}

Bambery, B., Selgelid, M., Maslen, H., Pollard, A., \& Savulescu, J. (2013). The Case for Mandatory Flu Vaccination. American Journal of Bioethics, 13(9), $38-40$.

Beard, F. H., Leask, J., \& McIntyre, P. B. (2017). No Jab, No Pay and Vaccine Refusal in Australia: The Jury Is Out. The Medical Journal of Austratia, 206(9), 381-383.

Bester, J. C. (2015). Vaccine Refusal and Trust: The Trouble with Coercion and Education and Suggestions for a Cure. Journal of Bioethical Inquiry, 12, $555-559$.

Blank, N. R., Caplan, A. L., \& Constable, C. (2013). Exempting Schoolchildren from Immunizations: States with Few Barriers Had Highest Rates of Nonmedical Exemptions. Health Affairs, 32(7), 1282-1290.

Brennan, J. (2018). A Libertarian Case for Mandatory Vaccination. Journal of Medical Ethics, 44, 37-43.

Camerer, C., \& Thaler, R. H. (1995). Anomalies: Ultimatums, Dictators, and Manner. Journal of Economic Perspectives, 9, 209-219.

Clarke, S., Giubilini, A., \& Walker, M. J. (2017). Conscientious Objection to Vaccination. Bioethics, 31(3), 155-161.

Dawson, A. (2007). Herd Protection as a Public Good: Vaccination and Our Obligations to Others. In A. Dawson \& M. Verweij (Eds.), Ethics, Prevention, and Public Health (pp. 160-178). Oxford: Clarendon Press. 
Flanigan, J. (2014). A Defense of Compulsory Vaccination. HEC Forum, 26, $5-25$.

Giubilini, A. (2014). The Paradox of Conscientious Objection and the Anemic Concept of Conscience. Downplaying the Role of Moral Integrity in Healthcare. Kennedy Institute of Ethics Journal, 24(2), 159-185.

Giubilini, A. (2016). Conscience. In E. N. Zalta (Ed.), The Stanford Encyclopedia of Philosophy (Winter 2016 ed.). Palo Alto: Stanford University Press.

Giubilini, A., Douglas, T., \& Savulescu, J. (2017). Liberty, Fairness, and the 'Contribution Model' for Non-medical Vaccine Exemption Policies: A Reply to Navin and Largent. Public Health Ethics, 10(3), 235-240.

Giubilini, A., Douglas, T., \& Savulescu, J. (2018). The Moral Obligation to Be Vaccinated: Utilitarianism, Contractualism, and Collective Easy Rescue. Medicine, Health Care, and Philosophy. https://doi.org/10.1007/s11019018-9829-y. Online first 10 Feb.

Guth, W., Schmittberger, R., \& Schwarze, B. (1982). An Experimental Analysis of Ultimatum Bargaining. Journal of Economic Behavior and Organization, 3, 367-388.

Higgins, L. (2016, January 28). More Michigan Parents Willing to Vaccinate Kids. Detroit Free Press. Retrieved April 30, 2018, from http://www.freep. com/story/news/education/2016/01/28/immunization-waivers-plummet40-michigan/79427752/

Italian Ministry of Health. (2018). I dati nazionali al 2017 sulle coperture vaccinali dell'eta' pediatrica e dell'adolescente. Available from http://www.salute. gov.it/portale/news/p3_2_1_1_1.jsp?lingua=italiano\&menu=notizie\&p=dal ministero\&id=3348. Last accessed 4 May 2018.

Mill, J. S. (1859). On Liberty. London: Walter Scott Publishing. In The Project Gutenberg Ebook of On Liberty. Available at https://www.gutenberg.org/ files/34901/34901-h/34901-h.htm

Nature. (2018). Laws Are Not the Only Way to Boost Immunization. Editorial Article. Nature, 553, 249-250.

Navin, M. (2015). Values and Vaccine Refusal: Hard Questions in Ethics, Epistemology, and Health Care. New York: Routledge.

Navin, M. C., \& Largent, M. A. (2017). Improving Nonmedical Vaccine Exemption Policies: Three Case Studies. Public Health Ethics, 10(3), 225-234.

Omer, S. B., et al. (2012). Vaccination Policies and Rates of Exemption from Immunization, 2005-2011. New England Journal of Medicine, 367, 1170-1171.

Pierik, R. (2016). Mandatory Vaccination: An Unqualified Defence. Journal of Applied Philosophy. https://doi.org/10.1111/japp.12215.

Rawls, J. (1971/1999). A Theory of Justice (Rev. ed.). Cambridge, MA: Harvard University Press. 
Rota, J. S., Salmon, D. A., Rodewald, L. E., Chen, R. T., Hibbs, B. F., \& Gangarosa, E. J. (2001). Processes for Obtaining Nonmedical Exemptions to State Immunization Laws. American Journal of Public Health, 91(4), 645-648. Salmon, D. A., \& Siegel, A. W. (2001). Religious and Philosophical Exemptions from Vaccination Requirements and Lessons Learned from Conscientious Objectors from Conscription. Public Health Reports, 116(4), 289-295.

Selgelid, M. (2009). A Moderate Pluralist Approach to Public Health Policy and Ethics. Public Health Ethics, 2(2), 195-205.

Tabibnia, G., \& Lieberman, M. D. (2007). Fairness and Cooperation Are Rewarding. Annals of the New York Academy of Sciences, 1118(1), 90-101.

Tabibnia, G., Satpute, A. B., \& Lieberman, M. D. (2008). The Sunny Side of Fairness: Preference for Fairness Activates Reward Circuitry (and Disregarding Unfairness Activates Self-Control Circuitry). Psychological Science, 19(4), 339-347.

Wang, E., Clymer, J., Davis-Hayes, C., \& Buttenheim, A. (2014). Nonmedical Exemptions from School Immunization Requirements: A Systematic Review. American Journal of Public Health, 104(11), e62-e84.

Open Access This chapter is licensed under the terms of the Creative Commons Attribution 4.0 International License (http://creativecommons.org/licenses/ by $/ 4.0 /$ ), which permits use, sharing, adaptation, distribution and reproduction in any medium or format, as long as you give appropriate credit to the original author(s) and the source, provide a link to the Creative Commons license and indicate if changes were made.

The images or other third party material in this chapter are included in the chapter's Creative Commons license, unless indicated otherwise in a credit line to the material. If material is not included in the chapter's Creative Commons license and your intended use is not permitted by statutory regulation or exceeds the permitted use, you will need to obtain permission directly from the copyright holder.

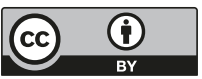

